SOUZA, L.A. et al. Retalho de avanço associado ao triângulo de bürrow após exerese de cisto infundibular em um cão: relato de caso. PUBVET, Londrina, V. 8, N. 22, Ed. 271, Art. 1813, Novembro, 2014.

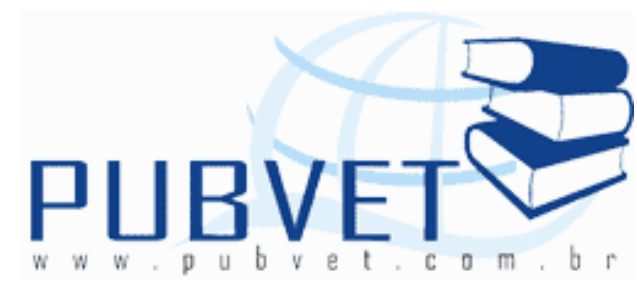

PUBVET, Publicações em Medicina Veterinária e Zootecnia.

\title{
Retalho de avanço associado ao triângulo de bürrow após exerese de cisto infundibular em um cão: relato de caso
}

Luiz Augusto de Souza ${ }^{1}$, Nadine Bou Fares ${ }^{2}$, Taís Andrade Dias ${ }^{3}$, Carolina Silva Ramos $^{4}$, Danilo Ferreira Rodrigues ${ }^{5}$, Tamires de Paula e Silva ${ }^{2}$ Laiz Alves Pereira $^{2}$, Luíza Fernandes de Sousa ${ }^{2}$

${ }^{1}$ Médico Veterinário. Professor adjunto I da Universidade Federal de Goiás. Escola de Veterinária da UFG. E-mail: souza_vet@yahoo.com.br

${ }^{2}$ Graduanda em Medicina Veterinária. Universidade Federal de Goiás (UFG)

${ }^{3}$ Médica Veterinária. Doutoranda em Ciência Animal. Universidade Federal de Goiás (UFG).

${ }^{4}$ Médica Veterinária. Professora Faculdades Objetivo (ASSOBES/IUESO)

${ }^{5}$ Médico Veterinário. Doutorando em Ciência Animal. Universidade Federal de Goiás (UFG).

\section{Resumo}

Os cistos cutâneos em cães e gatos são caracterizados por possuírem uma parede epitelial e pela presença de um conteúdo que geralmente é queratina. A maioria dos cistos possui origem folicular e tem prognóstico favorável. A remoção cirúrgica é recomendada e tem como resultado um amplo defeito cirúrgico que geralmente exige o conhecimento de técnicas de cirurgia plástica reconstrutiva para sua oclusão. O presente relato descreve o atendimento a uma cadela da raça Boxer que apresentava um nódulo na região da cabeça. 
SOUZA, L.A. et al. Retalho de avanço associado ao triângulo de bürrow após exerese de cisto infundibular em um cão: relato de caso. PUBVET, Londrina, V. 8, N. 22, Ed. 271, Art. 1813, Novembro, 2014.

Após exame clínico e laboratorial foi recomendada a extirpação do nódulo e realização do exame histopatológico. O procedimento cirúrgico realizado exigiu a execução de um retalho de avanço unilateral associado ao triângulo de Bürrow para aproximar as bordas da ferida cirúrgica que estavam em um local sobre alta tensão tecidual. No pós-operatório foi realizada bandagem sobre a mesma para evitar a formação de seroma. O exame histopatológico revelou se tratar de um cisto infundibular, comum em cães.

Palavras-chave: Boxer, Cirurgia plástica, Plexos subdérmicos, Nódulo cutâneo

\title{
Advancement flap associated to bürrow's triangle after removal of infundibular cyst in dog: case report
}

\begin{abstract}
Cutaneous cysts in dogs and cats are characterized by an epithelial wall and a content that generally is keratin. Most cysts have follicular origin and good prognostic. Surgical removal is recommended and as a result it has a large surgical defect that typically requires technical knowledge of reconstructive plastic surgery for occlusion. This report describes the case of a female boxer dog that had a nodule on the head. After clinical and laboratory examination was recommended removal of the lump and the execution of an histopathologic exam. The surgical procedure demanded to perform an unilateral advancement flap associated with Bürrow's triangle, to approach the wound edges that were under high tissue tension. In postoperative was made a bandage to avoid formation. The histopathologic exam revealed it to be an infundibular cyst, that is usual in dogs.
\end{abstract}

Keywords: Boxer, plastic surgery, subdermal plexus, cutaneous lumps

\section{INTRODUÇÃO}

Os cistos cutâneos são lesões não neoplásicas benignas comuns nos cães e rara nos gatos. São caracterizados por possuírem uma parede epitelial e pela 
SOUZA, L.A. et al. Retalho de avanço associado ao triângulo de bürrow após exerese de cisto infundibular em um cão: relato de caso. PUBVET, Londrina, V. 8, N. 22, Ed. 271, Art. 1813, Novembro, 2014.

presença de um conteúdo que geralmente é queratina (GROSS et al., 1992). A maioria dos cistos é de origem folicular e não há predileção por sexo ou idade. Dentre as raças acometidas e predispostas estão Boxer, Doberman, Shih-Tzu, Basset Hound e o Schnauzer. Os cistos foliculares são classificados em infundibular, istmo catagênico, matrical e híbrido, sua classificação dependerá do nível do folículo no qual se desenvolve (SOUZA, 2005).

Os cistos infundibulares também chamados de cistos epidermóides, se originam do infundíbulo do folículo piloso. É um cisto presente na derme, podendo estender-se para o interior do panículo adiposo com lesões que podem ser múltiplas ou isoladas. Histologicamente, os cistos infundibulares se caracterizam por uma parede cística formada por células com diferenciação em epitélio escamoso, essa cavidade é repleta de queratina lamelar distribuída de forma concêntrica (GROSS et al., 1992; SOUZA, 2005).

A nomenclatura sugere que os cistos são formados pelo resultado de um trauma, por fragmentos epidermais encravados ou ainda por anomalias congênitas do desenvolvimento da epiderme (GROSS et al., 1992). Em um estudo com avaliação de 571 cistos infundibulares, os locais afetados foram o membro anterior $(18,0 \%)$, membro posterior (16,5\%), abdômen $(14,5 \%)$, dorso $(11,4 \%)$, tórax $(11,2 \%)$, cabeça $(9,5 \%)$, pescoço $(6,7 \%)$, cauda $(3,8 \%)$, períneo $(2,8 \%)$ e escroto $(0,3 \%)$. Já os cistos múltiplos foram vistos em 5,3\% (SOUZA, 2005).

Como forma de tratamento, a remoção cirúrgica é recomendada na maioria dos casos de cistos cutâneos (YAGER et al., 1993). No entanto, tem como resultado a criação de uma ferida cirúrgica extensa que, geralmente, exige o conhecimento de técnicas de cirurgia plástica reconstrutiva para sua oclusão (ANGELI et al., 2006). O retalho de avanço é assim denominado de acordo com a direção de transferência, está próximo ao leito receptor e sempre é pediculado por ser composto de um segmento de pele e tecido subcutâneo adjacente. Podem ser utilizados para recobrir defeitos com má vascularização e nos quais ocorra a exposição de nervos, tendões e ossos. Além disso, evitam problemas associados à cicatrização por segunda intenção 
SOUZA, L.A. et al. Retalho de avanço associado ao triângulo de bürrow após exerese de cisto infundibular em um cão: relato de caso. PUBVET, Londrina, V. 8, N. 22, Ed. 271, Art. 1813, Novembro, 2014.

diminuindo o tempo de cicatrização da ferida e consequentemente a morbidade, além de evitar a formação de cicatrizes exuberantes, contraturas e frágil epitelização (ANGELI et al., 2006).

Dentro deste contexto, o objetivo deste relato foi discorrer sobre a técnica de retalho de avanço associada à execução do triângulo de Bürrow após remoção de um cisto infundibular na região da cabeça de um cão da raça Boxer.

\section{RELATO DE CASO}

Uma cadela da raça Boxer com dois anos de idade foi atendida no Hospital Veterinário da Universidade Federal de Goiás (HV/EVZ/UFG) apresentando um nódulo na região da cabeça, localizado acima do osso frontal. De acordo com o relato do proprietário, o nódulo apareceu ainda quando o animal era filhote após um traumatismo e, desde então, cresceu de forma progressiva, porém lenta. Durante o exame físico, observou-se que o nódulo tinha aproximadamente $5,0 \mathrm{~cm}$ de diâmetro, consistência macia, flutuante e com a mesma coloração da pele.

O animal se alimentava de ração comercial, as vacinas e a vermifugação estavam atualizadas. O proprietário relatou que o animal apresentava fezes com consistência e odor normais e a urina estava escura e com odor fétido. Não foi observado ectoparasitas, o animal apresentava estado de consciência alerta, as mucosas estavam normocoradas com o tempo de preenchimento capilar de dois segundos e temperatura retal de $39,3^{\circ} \mathrm{C}$. Com relação aos linfonodos palpáveis, todos se encontravam não reativos, turgor cutâneo, pele, ouvidos, olhos e anexos, sistema cardiovascular, respiratório e nervoso sem alterações. Exames laboratoriais foram solicitados e todos se encontravam dentro da normalidade. Tratando-se de um nódulo com origem desconhecida foi recomendado à remoção cirúrgica e em seguida o exame histopatológico da amostra, a fim de definir o diagnóstico.

Para realização do procedimento, o animal foi encaminhado para a sala de preparação onde recebeu os primeiros cuidados pré-operatórios. 
SOUZA, L.A. et al. Retalho de avanço associado ao triângulo de bürrow após exerese de cisto infundibular em um cão: relato de caso. PUBVET, Londrina, V. 8, N. 22, Ed. 271, Art. 1813, Novembro, 2014.

Inicialmente foi adquirido um acesso venoso por meio da veia cefálica com auxílio de um cateter $n^{\circ} 22$, e mantido em fluidoterapia com Ringer lactato. Como protocolo pré-anestésico foram administradas acepromazina, na dose de $0,05 \mathrm{mg} / \mathrm{kg}$; e meperidina 4,0mg/kg, por via intramuscular. Em seguida foi realizada ampla tricotomia delimitada pelos olhos, orelhas e osso occipital (Figura 1A). Já no centro cirúrgico, a indução anestésica foi realizada com propofol $1,0 \%$ (Diprivan ${ }^{\circledR}$ ) 4,0mg $\backslash \mathrm{kg}$ (IV) e o animal intubado com uma sonda orotraqueal acoplada ao circuito anestésico fechado com reinalação de gases. A manutenção durante todo o procedimento cirúrgico foi feita com anestésico inalatório isoflurano (Forane ${ }^{\circledR}$ ) vaporizado em $\mathrm{O}_{2}$ a $100 \%$.

Após antissepsia realizou-se incisão ao redor do nódulo com quatro ângulos retos formando um quadrado. Após secção e divulsão foi promovida a retirada do nódulo. Durante a dermorrafia foi observado que não seria possível reaproximar as bordas da ferida e suturá-la devido à alta tensão tecidual da região. Com o intuito de ocluir a ferida cirúrgica, optou-se pelo o uso da técnica do retalho de avanço associada à execução do triângulo de Bürrow, para diminuir a tensão no tecido que recebeu a sutura (Figura 1B). O tecido subcutâneo do retalho foi divulsionado com uma tesoura mantendo o plexo subdérmico junto ao retalho, o que garantiu o suprimento vascular para o leito receptor (Figura 2A). As bordas da ferida e do retalho foram reaproximadas com sutura em padrão interrompido simples com fio náilon n² 2-0 (Figura 2B). 
SOUZA, L.A. et al. Retalho de avanço associado ao triângulo de bürrow após exerese de cisto infundibular em um cão: relato de caso. PUBVET, Londrina, V. 8, N. 22, Ed. 271, Art. 1813, Novembro, 2014.
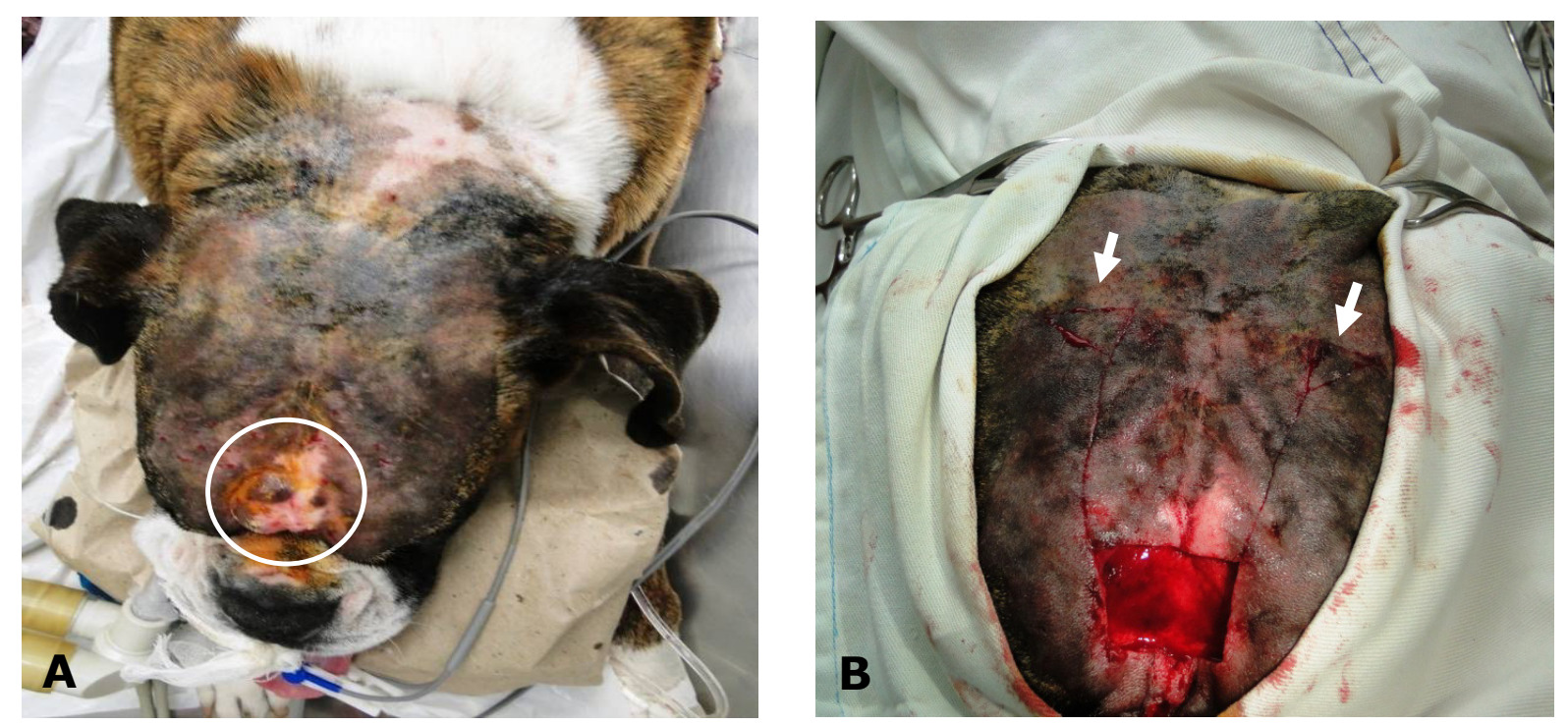

Figura 1: Cão da ração Boxer, dois anos de idade, submetido à excisão de um nódulo na região da cabeça. (A) Localização do nódulo após ampla tricotomia (circulo). (B) Ferida cirúrgica após remoção do nódulo, observar a extensão do retalho de avanço necessário para ocluir a ferida e a realização do triângulo de Bürrow (setas).
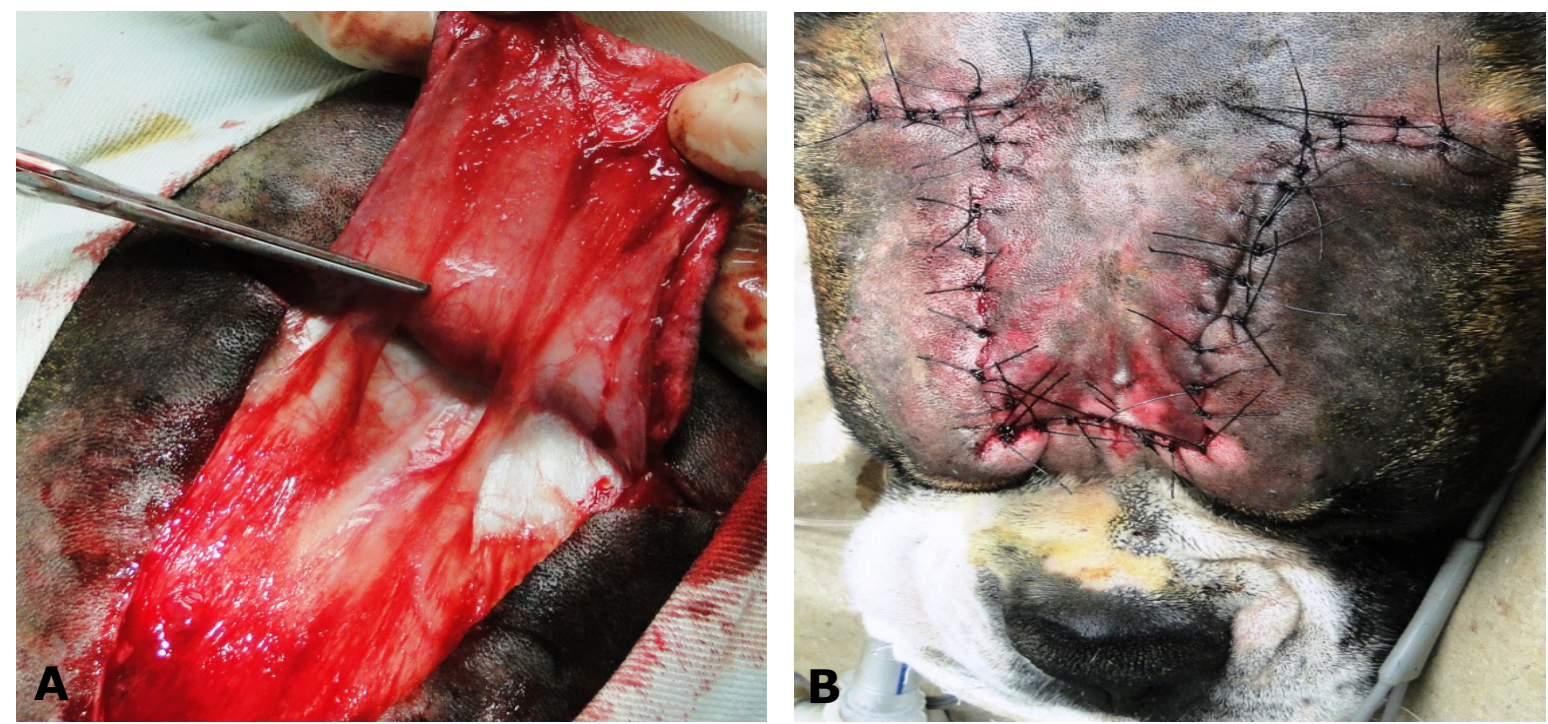

Figura 2: Cão da raça Boxer, dois anos de idade, submetido à excisão de um nódulo na região da cabeça. (A) Retalho de avanço com preservação do plexo subdérmico. (B) Oclusão da ferida cirúrgica com sutura interrompida simples com fio náilon n²-0. 
SOUZA, L.A. et al. Retalho de avanço associado ao triângulo de bürrow após exerese de cisto infundibular em um cão: relato de caso. PUBVET, Londrina, V. 8, N. 22, Ed. 271, Art. 1813, Novembro, 2014.

No pós-operatório imediato foi realizada compressa fria com gelo sobre a região por alguns minutos e, em seguida, higienização da ferida cirúrgica com água oxigenada e iodo povidine. Uma bandagem com gaze, algodão e faixa, envolvendo toda a cabeça do animal, deixando os olhos, orelhas, e focinho livres, foi confeccionada e trocada no quinto dia de pós-operatório. Foram prescritos Dipirona sódica $\left(\right.$ Dipidor $^{\circledR}$ ) na dose de $25,0 \mathrm{mg} \backslash \mathrm{kg}$, Meloxicam (Maxican ${ }^{\circledR}$ ) 0,1 mg $\backslash \mathrm{kg}$ ，Tramadol (Dorless $\mathrm{V}^{\circledR}$ ) 3,0mg $\backslash \mathrm{kg}$ e antimicrobiano Cefalexina (Lexin ${ }^{\circledR}$ ) $30,0 \mathrm{mg} / \mathrm{kg}$ durante 10 dias, todos por via oral. Os pontos da pele foram removidos após dez dias de pós-operatório, e dada alta médica.

O nódulo foi fragmentado e acondicionado em formol a 10\%, em seguida enviado ao laboratório de patologia para realização do exame histopatológico e confirmado o diagnóstico de cisto infundibular.

\section{DISCUSSÃO}

Cistos cutâneos apresentam predileção por determinadas raças de cães. Dentre as raças, SOUZA (2005) relata que cães da raça Boxer estão entre aquelas de predileção, corroborando com a raça descrita no presente relato. Com relação à localização destes cistos, autores como SOUZA (2005) e ZANIN et al. (2006) afirmaram que os locais de maior incidência são os membros e o pescoço. No entanto, o cisto aqui descrito apresentava-se localizado na cabeça. Tal informação não deve ser levada em consideração como casuística, uma vez que, trata-se de um caso isolado. A origem destes cistos pode estar relacionada a um trauma local, fato relatado pelo proprietário antes do aparecimento do nódulo.

Assim como YAGER et al. (1993), a remoção cirúrgica do cisto foi recomendada e o conhecimento de técnicas de cirurgia plástica reparadora se fez necessária. Por se tratar de amplas lesões cirúrgicas, ANGELI et al. (2006), afirmaram que a técnica do retalho de avanço é eficaz quando realizada paralelamente às linhas de menor tensão da cabeça, tal manobra cirúrgica facilitou o estiramento do retalho para frente e sobre a ferida cirúrgica, recobrindo-a. Além disso, foi realizada a divulsão profunda em relação à 
SOUZA, L.A. et al. Retalho de avanço associado ao triângulo de bürrow após exerese de cisto infundibular em um cão: relato de caso. PUBVET, Londrina, V. 8, N. 22, Ed. 271, Art. 1813, Novembro, 2014.

camada muscular do panículo para preservar plexos subdérmicos e vasos cutâneos diretos que correm paralelamente à superfície da pele. A técnica empregada promoveu o relaxamento das linhas de tensão da pele e facilitou o deslocamento do retalho cutâneo sobre a ferida de forma satisfatória. Segundo FOSSUM et al. (2008), esta divulsão deve ser bem executada, pois caso os plexos subdérmicos e vasos cutâneos diretos não sejam preservados há possibilidade de necrose do retalho no sitio receptor.

O cisto relatado poderia ter sido retirado por uma incisão circular, no entanto, FOSSUM et al. (2008) afirmaram que esse tipo de defeito tende a formar bordas evertidas da ferida cirúrgica conhecidas como "orelhas". A fim de evitar tal intercorrência, foi preconizada a técnica de correção de defeito retangular, chamada retalho de avanço unilateral, ou de pedículo único associada à execução do triângulo de Bürrow nas extremidades do retalho, que ainda segundo FOSSUM et al. (2008), auxilia no alívio da tensão das linhas de força da pele.

Conforme diagnosticado pelo exame histopatológico, o nódulo descrito tratava-se de um cisto infundibular com características histológicas compatíveis aos cistos descritos por SOUZA (2005) e ZANIN et al. (2006). Os autores, também relataram que este tipo de cisto é o mais encontrado na medicina veterinária. Em um estudo da casuística dos cistos cutâneos realizado por ZANIN et al. (2006) foram detectados 20 casos de cistos cutâneos, sendo 18 casos em cães e apenas dois casos em gatos. Constatou-se neste estudo que o cisto de maior frequência foi o cisto folicular infundibular (45\%) diagnóstico descrito no presente relato.

\section{CONCLUSÕES}

Todos os tipos de cistos, embora sendo lesões não neoplásicas benignas, são de grande relevância na clínica e cirurgia de pequenos animais, pois frequentemente requerem remoção cirúrgica e podem ter como resultado, feridas de grande extensão que necessitam de técnicas de cirurgia plástica para serem corrigidas. Por isso, o conhecimento das técnicas de retalho de 
SOUZA, L.A. et al. Retalho de avanço associado ao triângulo de bürrow após exerese de cisto infundibular em um cão: relato de caso. PUBVET, Londrina, V. 8, N. 22, Ed. 271, Art. 1813, Novembro, 2014.

avanço associada à execução do triângulo de Bürrow se faz necessária para o sucesso da cirurgia plástica reparadora.

\section{REFERÊNCIAS BIBLIOGRÁFICAS}

1. ANGELI, A. L.; BRANDÃO, C. V. S.; FREITAS, R. S. Cirurgia reconstrutiva: retalhos cutâneos em pequenos animais. MEDVEP - Revista científica de medicina veterinária, pequenos animais e animais de estimação, Curitiba, vol.4, n.12, p.87-95, 2006.

2. HEDLUND, C. S. Cirurgia do Sistema Tegumentar. In: FOSSUM, T. W. (3ed.) Cirurgia de Pequenos Animais. Rio de Janeiro: Elsevier, 2008. P. 192-222.

3. GROSS, T. L.; IHRKE, P. J.; WALDER, E. J. Veterinary Dermatopatology. A macroscopic and microscopic evaluation of canine and feline skin disease. Mosby Year Book, ST.Louis, 1992 , p.351-373.

4. SOUZA, T. M. Estudo retrospectivo de 761 tumores cutâneos em cães._296f. Dissertação (Mestrado em Medicina Veterinária) - Centro de Ciências da Saúde, UFSM, Santa Maria, 2005.

5. YAGER, J. A.; SCOTT, D. N.; NILCOCK, B. The skin and appendages. In: JUBB, K. V. F.; KENNEDY, P. C.; PALMER, N. C. Pathology of domestic animals._London Academy press, V.1, 1993.

6. ZANIN, A. A.; ROCKENBACH, I. A.; GUIM, T. N.; VAZ, S.; FERNANDES, C. G. Levantamento da casuística de cistos cutâneos em caninos e felinos no período de 2001 a 2006. In: CONGRESSO DE INICIAÇÃO CIENTÍFICA, 15., 2006, Pelotas. 